\title{
Use of English internet dictionaries in the learning process at the language faculty
}

\author{
Ekaterina Grigoryeva ${ }^{1 *}$ \\ ${ }^{1}$ Ivanovo State University, Foreign Philology Department, 39, Yermak Street, Ivanovo, \\ 153025, Russian Federation
}

\begin{abstract}
The article is devoted to online dictionaries of the subject area Food and Drinks and their usage in the educational process in the English lessons at the language faculty.
\end{abstract}

\section{Introduction}

Various information technologies are actively developing. Universal computerization is observed in various fields of science including lexicography. Electronic and Internet reference books are regularly published. The term cyberlexicography appeared. It is under study in the works of both Russian (O.M. Karpova, S.A. Manik and others) and foreign researchers (Bergenholtz H., De Shryver G.M. and others). The Internet contains general and special linguistic dictionaries, encyclopedias, terminological and non-terminological reference books, etc. The given research is dedicated to the problem of using dictionaries of the subject area Food and Drinks in the classroom.

When studying the topic Food and Drinks as well as related topics (for example, National cuisine of the country) various teaching aids (workbooks, cards, etc.) can be used. The dictionary can also become one of means of forming students' lexical skills and contribute to the speaking skills development.

\footnotetext{
* Corresponding author: grigoryeva.ekaterina@mail.ru
} 


\section{Objects and Methods.}

\subsection{Food glossaries}

The first dictionary to be taken for analysis is Cooking Glossary. Food Industry Terminology. The macrostructure is organized in alphabetical order and includes names of dishes (adobo, cabanossi, calabaza), drinks (café noir, malt, Kahlua, Kefir), kitchen utensils (absorbent paper, kitchen paper), dishes (caldero, flameproof, kettle), ingredients and food products, fruits and vegetables used in cooking (aceite de oliva, acidulated water, feijoa, filberts, Maguey), words denoting the cooking process (ice, pan-broil, restock, roast) and others.

The microstructure includes a lexical unit, a definition and an etymological label, which makes it possible to find out information about the origin of a lexical unit:

a la Greque (a la Grecqua) [French] means in the Greek manner. The term describes vegetables cooked in a mixture of oil and vinegar, or lemon juice, with seasoning added [https://theodora.com/food/index.html] [4].

Such a glossary can be useful for first-year students studying the topic Food and Drinks. The definitions presented in the glossary are comprehensive and detailed. However, the glossary lacks a wide range of labels and illustrative examples. But this fact is determined by the lexicographic form of glossary. For senior students the developed system of the semantic and functional characteristics of the word (the inclusion of phonetic, grammatical, regional labels) and examples demonstrating the functioning of the lexical unit in speech is of much importance.

\subsection{Illustrated food dictionaries}

Since modern students have a visual perception of reality special importance is attached to the polygraphic content of the reference book. In the works of Russian lexicographers (for example, O. M. Karpova) the term polygraphic semiotics is used. According to O. A. Germanova this term is understood as a set of fonts, colour designations, emblems that contribute to the successful work with a lexicographic manual [1].

In the dictionary by R.R.K. Hartmann and G. James the term illustration is defined in the following way: it is a drawing, diagram or photograph used to reveal the meaning of the concept [2].

Lexicographers also define the term an illustrated dictionary. According to the reference book, the illustrated dictionary includes graphics for specific words and phrases [2].

Illustrated reference books are popular and are published by leading foreign publishing houses: Cambridge, Oxford University Press, Pearson Education, Collins, etc.

One of such dictionaries is the Visual Dictionary Online. Food and Kitchen (MerriamWebster publishing house). The glossary is divided into two parts: Food and Kitchen.

The vocabulary of the Food section is organized in the following way: firstly, a general concept denoting a particular group of products (for example, mushrooms, fruits, vegetables, etc.) is given. By clicking on a general concept the user gets access to the lexemes included in this category: these are the names of spices, seasonings, cereals, etc.

This is how the microstructure for the lexeme Fruits looks like:

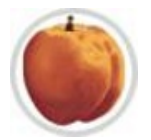

Fig. 1 Fruits 


\section{Fruits}

Usually sweet vegetables, primarily consumed at breakfast, as a snack or for a dessert, and used extensively in pastry and candy making [5].

Several sections follow which in turn are subdivided into subsections: Berries (gooseberry, currant, bilberry, strawberry, blackberry), Stone Fruits (nectarine, apricot, peach), Dry Fruits (walnut, coconut, almond), Citrus Fruits (orange, pomelo, grapefruit), etc.

The microstructure includes a lexical unit, a definition, a pronunciation label (audio file), and a graphic illustration:

\section{orange}

widely available, it is often eaten plain or in juice, and it goes well with duck; it yields a flavor essence and an essential oil [5].

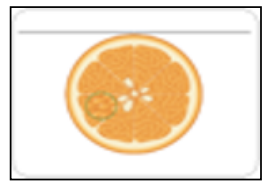

Fig. 2. Section of an orange

If you click on the section of an orange link, you will see a graphic image of the inside of the orange indicating the names of orange components. For each component a definition and an audio track are given. Clicking on an audio-file the user will receive information about the unit pronunciation.

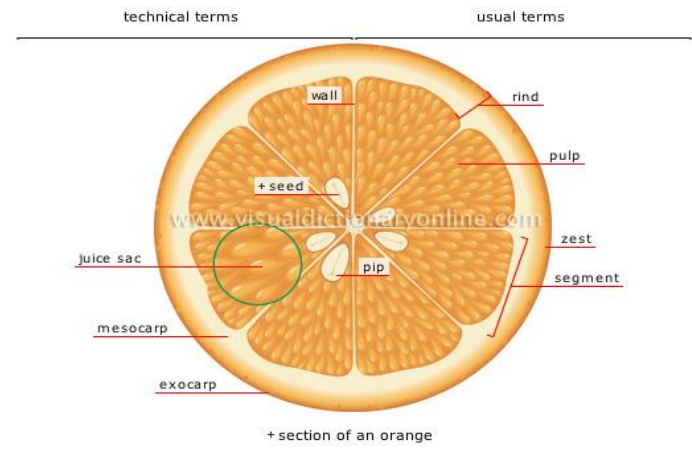

Fig. 3. The interior part of the orange

The second part of the dictionary is called Kitchen. The macrostructure includes lexemes that indicate the way of cooking, kitchen utensils (for example, glassware, kitchen knives, etc.).

The advantage of the reference book is the thematic organization of the material. Words related to food and drinks are arranged in groups. This organization contributes to the rapid assimilation of lexical material. Another advantage is the addition of pronunciation labels. Visual clarity contributes to the formation of the student's lexical skills. 


\subsection{Defining English dictionaries}

When studying the topic Food and Drinks in a deep way at the Faculty of Languages one should pay attention to the defining dictionaries. Topical parts are found in English explanatory dictionaries of the leading British publishers. For example, Cambridge Dictionary Online includes lists called Smart Vocabulary: Related Words and Phrases. Words are formed into a cloud by subject. By clicking on one or another unit in the cloud, the user gets access to the dictionary entry.

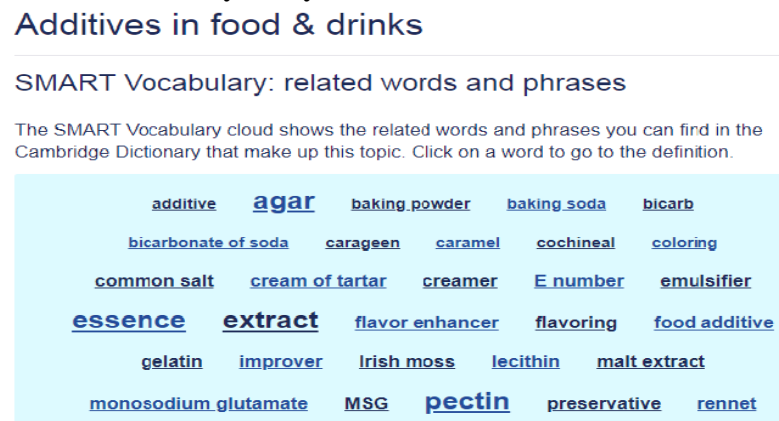

Fig. 4. Additives in food and drinks

This represents a cloud for the Food and Drink Additives theme. Since this is an explanatory dictionary, the microstructure includes not only the lexical unit and definition, but also labels (pronouncing, regional, grammatical (indicating the part of speech), thematic), illustrative example and graphic representation. The vocabulary entry contains an indication of the level in terms of language proficiency according to the European Framework of Reference (in the example below, this is A1 - the initial level).

salt noun US / sa:lt / UK / splt / A1

a common white substance found in sea water and in the ground, used especially to add flavor to food or to preserve it: Can you pass the salt, please? [https://dictionary.cambridge.org/dictionary/english/salt?q=salt+] [3].

A dictionary like this is an ideal reference book for students studying English at a high level. The inclusion of information categories, illustrative examples allows you to get acquainted with the different sides of the lexeme and understand the context of its use.

\subsection{Methods}

The following methods were used in the process of making a research: dictionary criticism, analytical method, statistic method and deductive method.

\section{Results}

The analysis of Internet dictionaries of the English language of the thematic group Food and Drinks shows that these dictionaries can be used in foreign language classes at a university. In the first courses of study you can use glossaries where a dictionary entry includes a word and its definition. At more serious levels, preference should be given to explanatory dictionaries with a developed system of information categories. The use of illustrated dictionaries contributes to the better visual perception of information and memorization of vocabulary. 


\section{Conclusion}

Using Internet dictionaries of different thematic groups in the process of studying is becoming more and more popular nowadays. Such dictionaries can be effectively used at schools and at Universities. The implementation of dictionaries into the learning process contributes to a better acquirement of new lexical units by students. The systems of exercises introduced in many dictionaries help to remember the lexis in a better way. The pictures in the dictionary used to illustrate the meaning of words is a popular method of introducing vocabulary.

\section{Acknowledgments}

This paper was financially supported by the Russian Foundation for Basic Research, grant No. 20-012-22046.

\section{References}

1. O. A. Germanova, Illustrated and Illustrative Dictionaries: Formation, Development, Current State (Ivanovo, 2011)

2. R. R. K. Hartmann, G. James, Dictionary of Lexicography (London and New York: Routledge, 1998)

3. Cambridge Dictionary Online. URL: https://dictionary.cambridge.org/us/

4. Cooking Glossary. Food Industry Terminology. URL: https://theodora.com/food/index.html

5. Merriam-Webster Visual Dictionary Food and Kitchen. URL: http://www.visualdictionaryonline.com/food-kitchen/food.php 